\title{
Journal of \\ Medicinal \\ Human Serum Albumin Binding in a Vial: A Novel UV-pH Titration Method To Assist Drug Design
}

\author{
Gergö Dargó, Dávid Bajusz, Kristóf Simon, Judit Müller, and György T. Balogh* \\ Cite This: https://dx.doi.org/10.1021/acs.jmedchem.0c00046 \\ Read Online
}

ABSTRACT: The knowledge on human serum albumin (HSA) binding is of utmost importance as it affects pharmacokinetic behavior and bioavailability of drugs. In this article, we report a novel method to screen for ionizable molecules with high HSA binding affinity based on $\mathrm{pK}_{\mathrm{a}}$ shifts using UV-pH titration. We investigated the HSA binding of 27 drugs and compared the results to experimental data from conventional methods. In most cases, significant shifts $\left(\Delta \mathrm{p} K_{\mathrm{a}}>0.1\right)$ were observed for drugs with high HSA binding, while no change could be detected for low-affinity binders. We showed the pivotal role of ionization centers in the formation of strong interactions between drug and HSA using molecular docking studies. We also verified our findings by testing five modified analogues designed by structural considerations. Significant decreases in their HSA binding proved that the UV-pH titration method combined with an in silico support can be used as a medicinal chemistry tool to assist rational molecular design.

\section{INTRODUCTION}

Active pharmaceutical ingredients (API) entering the systematic circulation may interact with various components of the blood, which directly affects their pharmacokinetic and pharmacodynamic behaviors. ${ }^{1-5}$ Blood plasma consists of approximately $7-9 \%$ of plasma proteins (albumins, glycoproteins, and fibrinogen), which contribute a major part to API-specific interactions. Among them, human serum albumin (HSA) is the most abundant (about 54-60\% of blood proteins) ${ }^{6-8}$ which is present in the blood at particularly high concentrations $(35-50 \mathrm{~g} / \mathrm{L}) .^{8-11}$ It plays an important role in maintaining the osmotic pressure of the blood, serves as a transport protein for endogenous substances (e.g., fatty acids and steroid hormones), and it is also the main contributor to the binding of drug molecules. ${ }^{5,7,8,10}$ The protein's heartshaped structure is composed of three main domains (I-III), each containing two subdomains (A and B) ${ }^{8-10}$ Besides the several recently identified low- to high-affinity binding sites of $\mathrm{HSA}^{12,13}$ the two specific drug binding sites (site I: warfarin site on the IIA subdomain and site II: indole-benzodiazepine site on the IIIA subdomain) are considered to be the most significant, regarding plasma protein binding. ${ }^{8,11,14-18}$ Drug molecules usually form reversible complexes with HSA by electrostatic and hydrophobic interactions. These HSA-API complexes cannot cross biological membranes; therefore, they become therapeutically inactive. ${ }^{5,19}$ Moreover, strong binding may also have a significant effect on the pharmacokinetic (PK) behavior of APIs (e.g., altered clearance, ${ }^{20-22}$ distribution, ${ }^{19-21}$ drug-drug interactions, ${ }^{19,23}$ and toxicity $\left.{ }^{24}\right)$. The HSA binding

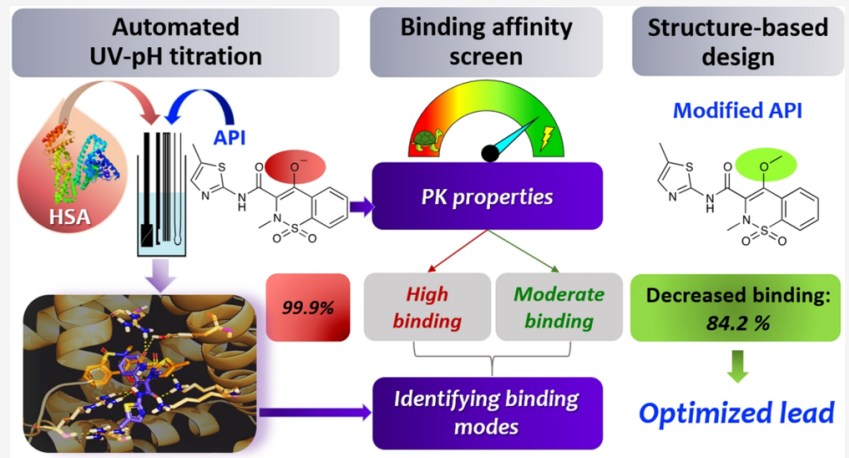

affinity shows wide diversity for drug-like compounds; thus, it is essential to predict the unbound fraction of APIs from the early stages of drug discovery for the estimation of PK behavior.

For the measurement of HSA-binding properties of APIs, several in vitro methods exist, ${ }^{18,19,25-27}$ including equilibrium dialysis (ED), ${ }^{28,29}$ ultrafiltration (UF), ${ }^{30}$ ultracentrifugation, ${ }^{31}$ chromatographic methods, ${ }^{32-35}$ NMR spectroscopy, ${ }^{36,37} \mathrm{X}$-ray crystallography, ${ }^{38}$ capillary electrophoresis (CE), ${ }^{39}$ etc. These methods differ in throughput and time of the measurement have different sample requirements and limitations, and each has its advantages and disadvantages (Table 1.). Also, most of the methods are able to provide information solely about the APIs' affinity to HSA, while structural information regarding the interactions between HSA and APIs can be acquired by only a few timely and expensive techniques (e.g., NMR and Xray diffraction). Besides the experimental methods, in silico models can be used to predict HSA binding, while molecular modeling studies can also be used to explore possible binding modes between HSA and APIs, providing additional structural information on complex formation. ${ }^{40}$ To give a thoroughly detailed description of the complexes, data from orthogonal

Received: January 10, 2020

Published: January 29, 2020 
Table 1. Summary of Commonly Used Experimental Methods for the Investigation of HSA-API binding ${ }^{18,19,25-27 a}$

\begin{tabular}{|c|c|c|}
\hline method type & $\begin{array}{l}\text { measurement time/ } \\
\text { throughput }\end{array}$ & pros \\
\hline \multicolumn{3}{|l|}{ Quantitative Binding Data } \\
\hline $\begin{array}{l}\text { chromatography and capillary } \\
\text { electrophoresis } 32-35,39\end{array}$ & $0.5 \mathrm{~h} / \mathrm{API} \mathrm{HT}$ & $\begin{array}{l}\text { accurate results } \\
\text { no NSB, volume shift, or membrane } \\
\text { leakage }\end{array}$ \\
\hline membrane separation methods & & reliable results \\
\hline equilibrium dialysis (ED) & 3 to $24 \mathrm{~h}$ & \\
\hline $\begin{array}{l}\text { rapid equilibrium dialysis } \\
(\text { RED })^{28,29}\end{array}$ & 2-7 h HT & $\begin{array}{l}\text { reaching equilibrium faster than ED } \\
\text { small volumes can be measured } \\
\text { NSB and volume shifts minimalized }\end{array}$ \\
\hline ultrafiltration $(\mathrm{UF})^{30}$ & $1-2 \mathrm{~h} \mathrm{HT}$ & $\begin{array}{l}\text { fast separation of free and protein- } \\
\text { bound API } \\
\text { small volumes can be measured } \\
\text { good approximation of physiological } \\
\text { conditions }\end{array}$ \\
\hline ultracentrifugation $^{31,42}$ & $10-24 \mathrm{~h} \mathrm{MT}$ & moderate NSB and Donnan effect \\
\hline
\end{tabular}

Structural Information $\mathrm{X}$-ray crystallography ${ }^{38}$ days to months, LT yields the most accurate structural information

binding sites can be identified

Binding and Structural Information $\mathrm{NMR}^{36,37}$ hours to days, LT

$0.5 \mathrm{~h}^{b}$ to $1-2 \mathrm{~h} \mathrm{MT}$ noninvasive technique

no separation step or subsequent measurement needed

UV-pH titration fast method for screening

may provide additional structural information of binding

APIs with low aqueous solubility can be measured nonbiological systems

calibration of immobilized HSA column is needed before measurements

high solvent consumption and waste generation

poor sensitivity for low-binding APIs

expensive chiral columns

Gibbs-Donnan effects

NSB on filter membranes and plastic devices

possible leakage of membrane

subsequent HPLC measurements

long time to reach equilibrium

volume shifts during incubation

dilution effects

possible leakage of membrane

plate accessories can be expensive (although inexpensive devices have been developed ${ }^{41}$ )

NSB on filter membrane and device

possibility of molecular sieving

$\mathrm{pH}$ and temperature controls are more difficult

time-consuming, careful $\mathrm{pH}$ and temperature controls are needed

errors due to the Johnston-Ogston effect

sedimentation of unbound API may occur

sample harvesting is difficult due to the floating lipid layer

expensive instrumentation

impurities of the protein may hinder crystallization

difficulty to determine correct crystallization conditions solubility problems of API may arise

precipitation or growth of tiny crystals may occur

\section{APIs with low aqueous solubility cannot be measured in physiological buffers}

only ionizable molecules can be measured

absorbance of HSA may interfere

${ }^{a}$ API, active pharmaceutical ingredient; NSB, nonspecific binding; HT, high throughput; MT, medium throughput; and LT, low throughput. ${ }^{b}$ If aqueous $\mathrm{p} K_{\mathrm{a}}$ values without HSA have already been determined.

methods are needed to be evaluated and compared simultaneously.

This study aims to present a UV-pH titration method as a novel approach to screen for high-affinity HSA-binding ionizable APIs. By means of the method, additional structural information might also be gathered, and the role of ionization centers in the interaction between HSA and APIs can be further elucidated to help medicinal chemists in their efforts toward rational molecular design.

Theoretical Basis of UV-pH Titration. Spectrophotometry can be applied for the measurement of proton dissociation constants $\left(\mathrm{p} K_{\mathrm{a}}\right)$ provided that the compound has a chromophore in proximity to the ionization center and the absorbance changes sufficiently as a function of $\mathrm{pH}$. In aqueous solutions, the dissociation equilibrium of a monoprotic acid and the acid dissociation constant $\left(K_{\mathrm{a}}\right)$ can be written as

$$
\begin{aligned}
& \mathrm{HA} \rightleftharpoons \mathrm{A}^{-}+\mathrm{H}^{+} \\
& K_{\mathrm{a}}=\frac{\left[\mathrm{A}^{-}\right]\left[\mathrm{H}^{+}\right]}{[\mathrm{HA}]}
\end{aligned}
$$

where $\mathrm{HA}$ and $\mathrm{A}^{-}$are the neutral and dissociated forms of the acid, respectively. After rearrangement of eq 2 and taking logarithms, we acquire the Henderson-Hasselbalch equation

$$
\mathrm{pH}=\mathrm{p} K_{\mathrm{a}}+\log \left(\frac{\left[\mathrm{A}^{-}\right]}{[\mathrm{HA}]}\right)
$$

If there is a $\mathrm{pH}$-dependent change in absorbance, the ratio of $\mathrm{HA}$ and $\mathrm{A}^{-}$can be determined spectrophotometrically. ${ }^{43}$ At a $\mathrm{pH}$ where the molecule exists entirely in its neutral form, its absorbance at a given wavelength is given by 

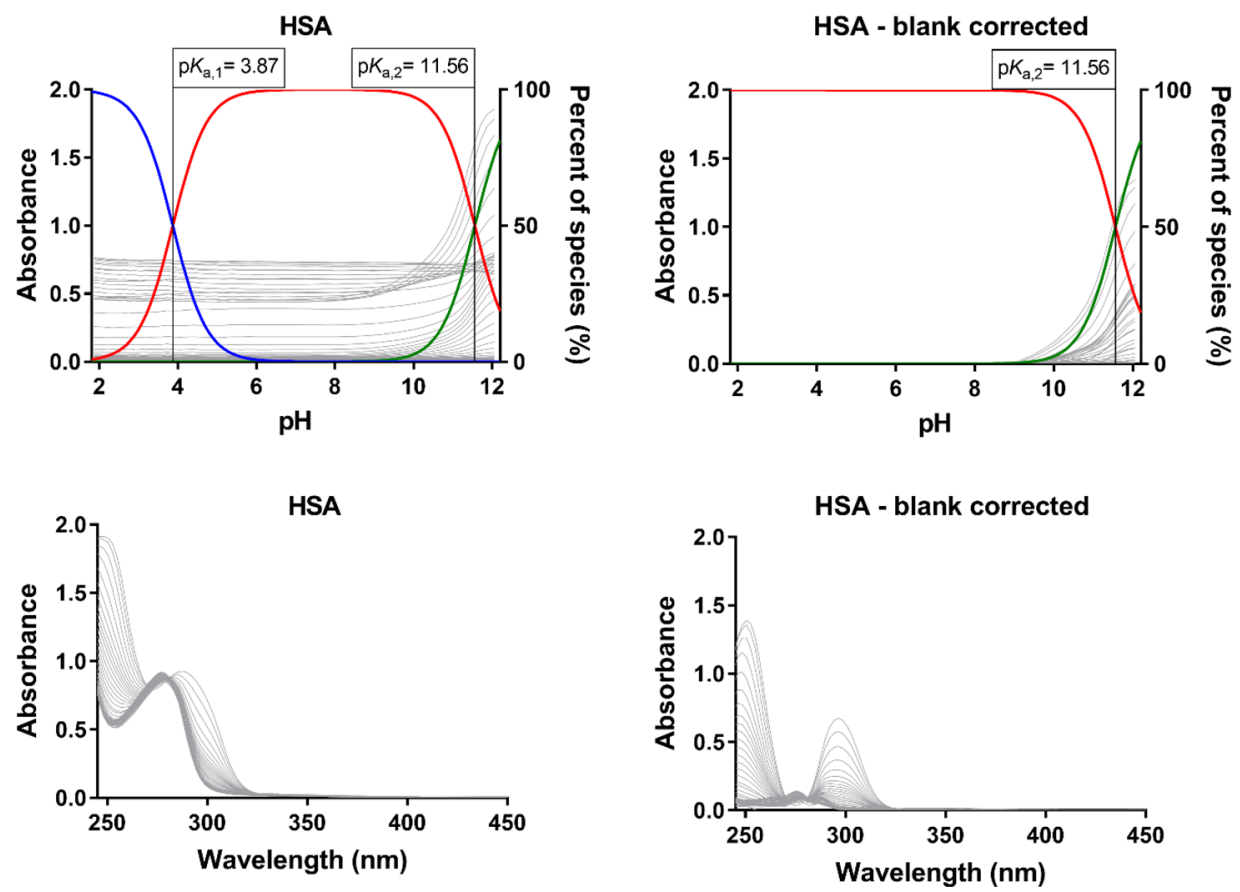

Figure 1. $\mathrm{pH}$-dependent UV-vis absorbance changes and detectable $\mathrm{p} K_{\mathrm{a}}$ values of HSA in the absence (left) and in the presence (right) of blank correction.

$$
A_{\mathrm{HA}}=\varepsilon_{\mathrm{HA}} \times l \times[\mathrm{HA}]
$$

where $\varepsilon_{\mathrm{HA}}$ and $[\mathrm{HA}]$ are the molar absorption coefficient and concentration of $\mathrm{HA}$, respectively, and $l$ is the optical path length. At a $\mathrm{pH}$ where the molecule exists entirely in its dissociated form, the absorbance of $\mathrm{A}^{-}$is given by

$$
A_{\mathrm{A}^{-}}=\varepsilon_{\mathrm{A}^{-}} \times l \times\left[\mathrm{A}^{-}\right]
$$

where $\varepsilon_{\mathrm{A}^{-}}$and $\left[\mathrm{A}^{-}\right]$are the molar absorption coefficient and concentration of $\mathrm{A}^{-}$, respectively. At an intermediate $\mathrm{pH}$ where both species are present, the absorbance is given as

$$
A_{\mathrm{i}}=\varepsilon_{\mathrm{HA}} \times l \times[\mathrm{HA}]+\varepsilon_{\mathrm{A}^{-}} \times l \times\left[\mathrm{A}^{-}\right]
$$

Combining eqs $4-6$, the ratio of $\mathrm{HA}$ and $\mathrm{A}^{-}$can be written as

$$
\frac{\left[\mathrm{A}^{-}\right]}{[\mathrm{HA}]}=\frac{A_{\mathrm{i}}-A_{\mathrm{HA}}}{A_{\mathrm{A}^{-}}-A_{\mathrm{i}}}
$$

Combining eqs 3 and 7 provides a modified HendersonHasselbalch equation, which can be used to calculate $\mathrm{p} K_{\mathrm{a}}$ values based on absorbance changes ${ }^{43}$

$$
\mathrm{pH}=\mathrm{p} K_{\mathrm{a}}+\log \left(\frac{A_{\mathrm{i}}-A_{\mathrm{HA}}}{A_{\mathrm{A}^{-}}-\mathrm{A}_{\mathrm{i}}}\right)
$$

If the conditions for UV-pH measurements coincide, then this method is the fastest way for the determination of $\mathrm{pK}$ values (approximately $20-25 \mathrm{~min} / 3$ parallel measurements). Furthermore, the sample requirement of built-in UV-pH methods of the SiriusT3 instrument is also minuscule, and only $5 \mu \mathrm{L}$ of a $10 \mathrm{mM}$ stock solution (DMSO, $\mathrm{MeCN}$, etc.) of the API is needed in a titration volume of $1 \mathrm{~mL}$. Also, measurements in the presence of co-solvents, macromolecules, or additives may be possible, making it an ideal choice for complexation studies as well.

Upon complexation with macromolecules (e.g., cyclodextrins, crown ethers, proteins, etc.), the dissociation equilibrium and the acid dissociation constant can be written as

$$
\begin{aligned}
& \mathrm{HA} \cdot \mathrm{G} \rightleftharpoons \mathrm{A} \cdot \mathrm{G}^{-}+\mathrm{H}^{+} \\
& K_{\mathrm{a}}^{*}=\frac{\left[\mathrm{A} \cdot \mathrm{G}^{-}\right]\left[\mathrm{H}^{+}\right]}{[\mathrm{HA} \cdot \mathrm{G}]}
\end{aligned}
$$

where $\mathrm{G}$ is the guest molecule, and $K_{\mathrm{a}}^{*}$ is the apparent proton dissociation constant of the complexed API. Due to different absorption properties of the complexed species, a significant spectral change may occur. ${ }^{44}$ If absorption of the guest molecule is negligible and addition of absorbances is assumed, then the absorbances of the molecular species can be given as

$$
\begin{aligned}
A_{\mathrm{HA}}= & \varepsilon_{\mathrm{HA}} \times l \times[\mathrm{HA}]+\varepsilon_{\mathrm{HAG}} \times l \times[\mathrm{HA} \cdot \mathrm{G}] \\
A_{A^{-}}= & \varepsilon_{\mathrm{A}^{-}} \times l \times\left[\mathrm{A}^{-}\right]+\varepsilon_{\mathrm{AG}^{-}} \times l \times\left[\mathrm{A} \cdot \mathrm{G}^{-}\right] \\
A_{\mathrm{i}}= & \varepsilon_{\mathrm{HA}} \times l \times[\mathrm{HA}]+\varepsilon_{\mathrm{HAG}} \times l \times[\mathrm{HA} \cdot \mathrm{G}] \\
& +\varepsilon_{\mathrm{A}^{-}} \times l \times\left[\mathrm{A}^{-}\right]+\varepsilon_{\mathrm{AG}^{-}} \times l \times\left[\mathrm{A} \cdot \mathrm{G}^{-}\right]
\end{aligned}
$$

Substituting eqs $11-13$ into eq 8 , the apparent $\mathrm{p} K_{\mathrm{a}}$ values $\left(\mathrm{p} K_{\mathrm{a}, \mathrm{app}}\right)$ can be calculated with shifts from $\mathrm{p} K_{\mathrm{a}}$ values that are proportional to the ratio of bound and unbound fractions.

\section{RESULTS AND DISCUSSION}

HSA-Binding Measurements by UV-pH Titration. We investigated the possibility of measuring HSA binding of APIs based on changes of proton dissociation constants of their free and complexed molecular forms using UV-pH titration. First, we collected UV-vis absorbance data of HSA during the UV$\mathrm{pH}$ titration assay to determine if the presence of HSA would interfere with the signal of APIs. As can be seen in Figure 1 (left), HSA has two $\mathrm{p} K_{\mathrm{a}}$ values $\left(\mathrm{p} K_{\mathrm{a} 1}=3.87\right.$ and $\left.\mathrm{p} K_{\mathrm{a} 2}=11.56\right)$, which are measurable by UV-pH titration. If we add HSA to the blank UV-pH titration assay (Figure 1, right), it annuls the spectral changes belonging to the first $\mathrm{p} K_{\mathrm{a}}$ value; however, the 

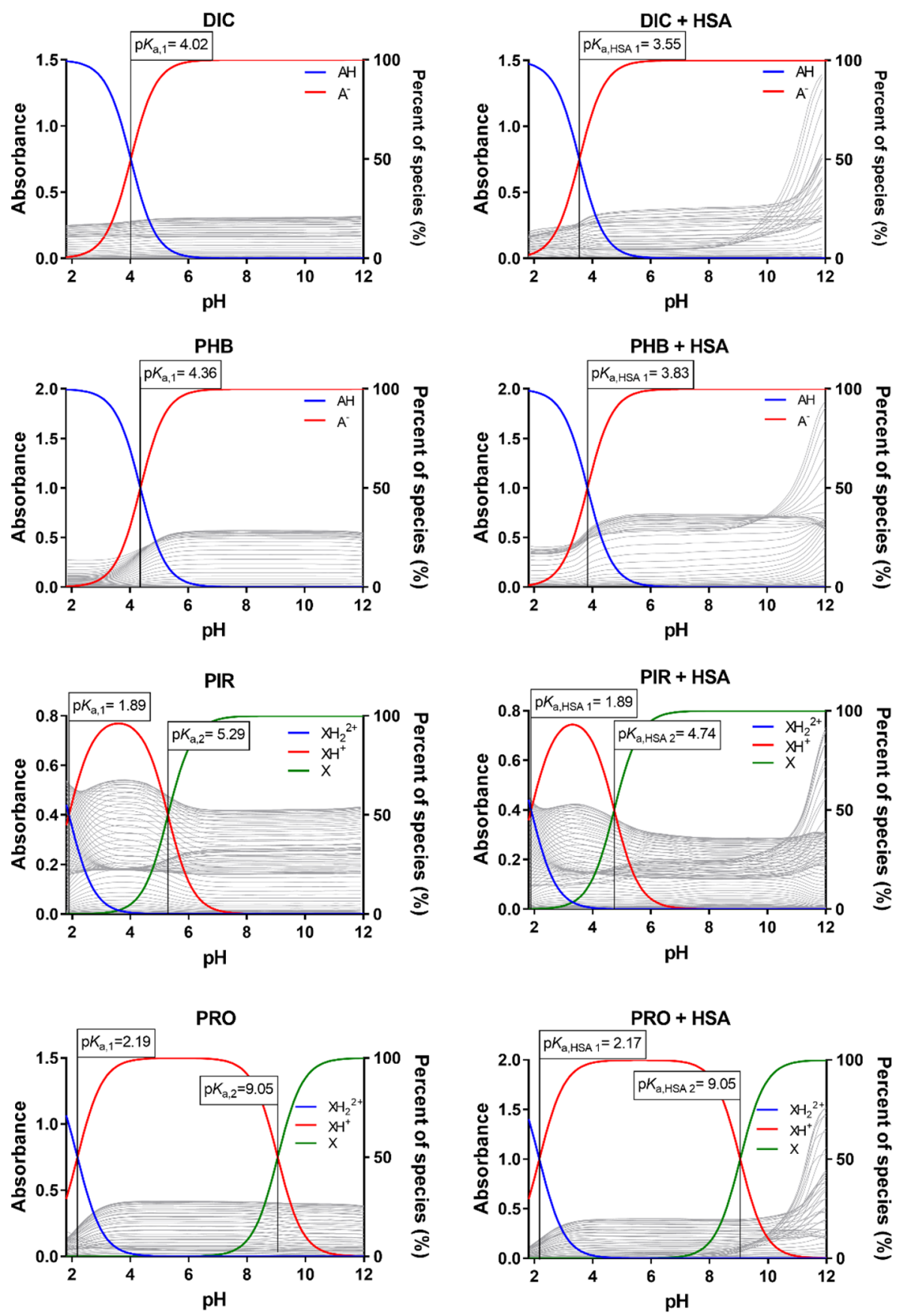

Figure 2. Absorbance spectra and detectable $\mathrm{p} K_{\mathrm{a}}$ values of diclofenac (DIC), phenylbutazone (PHB), piroxicam (PIR), and procaine (PRC) in the presence and absence of HSA.

second $\mathrm{pK}_{\mathrm{a}}$ value remains detectable even after blank correction. Therefore, even though the intensity of the signals of the second $\mathrm{p} K_{\mathrm{a}}$ value is decreased, we must consider the presence of overlapping absorption bands during titrations of APIs.

Next, we investigated HSA binding of APIs by measuring their $\mathrm{p} K_{\mathrm{a}}$ values in aqueous medium in the absence of HSA and in the presence of HSA $\left(\mathrm{pK}_{\mathrm{a}, \mathrm{HSA}}\right)$. Figure 2 shows some examples of the acquired spectra and experimental $\mathrm{p} K_{\mathrm{a}}$ values in the presence and absence of HSA. We observed significant $\mathrm{p} K_{\mathrm{a}}$ shifts $\left(\Delta \mathrm{p} K_{\mathrm{a}}\right)$ for several APIs, while others showed no change of $\mathrm{p} K_{\mathrm{a}}$ values upon addition of HSA (Table 2 and Table S1, Supporting Information). In the case of molecules with multiple protonation centers, their $\mathrm{p} K_{\mathrm{a}}$ values changed to varying extent; we proposed that this might indicate which part of the molecule contributes more to the binding to HSA. This was later confirmed by molecular docking studies (see the next section for further details). In some cases, absorption bands of HSA suppressed the absorbance of the API; therefore, $\mathrm{p} K_{\mathrm{a}, \mathrm{HSA}}$ could not be determined. This usually occurred in the case of APIs with only minuscule $\mathrm{pH}$-dependent absorbance changes in their spectrum in aqueous medium (e.g., diltiazem, imipramine, indomethacin, and propranolol) or in the case of $\mathrm{p} K_{\mathrm{a}}$ values higher than $\sim 10$ (e.g., furosemide $\mathrm{p} K_{\mathrm{a} 2}$ and amodiaquine $\mathrm{p} K_{\mathrm{a} 3}$ ) where the signals of $\mathrm{p} K_{\mathrm{a} 2}$ of HSA interfered. We could avoid this latter problem if the API had significant absorption at wavelengths higher than $320 \mathrm{~nm}$ (e.g., chloroquine $\mathrm{pK}_{\mathrm{a} 2}$, nitrazepam $\mathrm{p} K_{\mathrm{a} 2}$, and oxazepam $\mathrm{p} K_{\mathrm{a} 2}$ ), 
Table 2. Literature Data and Experimental Values of HSA Binding by Chromatographic, Rapid Equilibrium Dialysis (RED), and UV-pH Titration Measurements

\begin{tabular}{|c|c|c|c|c|c|c|}
\hline \multirow[b]{3}{*}{ API name } & \multicolumn{2}{|c|}{ literature data } & \multicolumn{4}{|c|}{ experimental data } \\
\hline & \multirow[b]{2}{*}{$\mathrm{PPB} \%{ }^{4,45-47}$} & \multirow[b]{2}{*}{ HSA\% (HPLC) $)^{48,49}$} & \multirow[b]{2}{*}{ HSA\% (HPLC) } & \multirow[b]{2}{*}{ HSA\% (RED) } & \multicolumn{2}{|c|}{ UV-pH titration } \\
\hline & & & & & $\Delta \mathrm{p} K_{\mathrm{a} 1}$ & $\Delta \mathrm{p} K_{\mathrm{a} 2}$ \\
\hline amodiaquine & & & 78.8 & & $0.12 \pm 0.04$ & $0.64 \pm 0.03$ \\
\hline cefuroxime & $33 \pm 3 ; 31.5$ & & 40.1 & & n.d. ${ }^{a}$ & n.d. ${ }^{a}$ \\
\hline chloroquine & $(S): 66.6 \pm 3.3$ & & $50.5^{b}$ & & $0.21 \pm 0.03$ & $0.75 \pm 0.05$ \\
\hline & $(R): 42.7 \pm 2.1$ & & & & & \\
\hline diazepam & $98.7 \pm 0.2 ; 99$ & 93.2 & 89.2 & n.d. ${ }^{c}$ & $0.09 \pm 0.03$ & \\
\hline diclofenac & $>99.5 ; 99.5$ & 99.0 & 100.0 & $95.8 \pm 0.2$ & $0.47 \pm 0.01$ & \\
\hline diclofenac ethyl ester & & & 98.1 & n.d. ${ }^{c}$ & & \\
\hline diflunisal & 99 & 98.7 & 100.0 & $\sim 100$ & $0.38 \pm 0.04$ & n.d. ${ }^{a}$ \\
\hline diflunisal ethyl ester & & & 97.5 & n.d. ${ }^{c}$ & & \\
\hline diltiazem & 78 & 53.9 & 56.6 & & n.d. ${ }^{a}$ & \\
\hline famotidine & 20 & 14.5 & 25.1 & $4.4 \pm 2.6$ & $0.02 \pm 0.03$ & \\
\hline furosemide & 98.4 & 63.8 & 99.4 & & $0.10 \pm 0.01$ & n.d. ${ }^{a}$ \\
\hline imipramine & $90.1 \pm 1.4 ; 92.6$ & 83.1 & 84.9 & & n.d. ${ }^{a}$ & \\
\hline indomethacin & $90 ; 92-99$ & 99.5 & 100.0 & $95.8 \pm 0.2$ & n.d. ${ }^{a}$ & \\
\hline isoniazid & $\sim 0$ & 6.8 & 10.9 & & $0.05 \pm 0.03$ & n.d. ${ }^{a}$ \\
\hline isoxicam & & & 97.3 & $80.4 \pm 0.8$ & $0.22 \pm 0.05$ & \\
\hline lornoxicam & & & 100.0 & $98.0 \pm 0.2$ & $0.87 \pm 0.23^{d}$ & $1.00 \pm 0.07$ \\
\hline meloxicam & 99 & & 99.9 & $96.7 \pm 0.1$ & $0.16 \pm 0.23^{d}$ & $0.55 \pm 0.05$ \\
\hline O-methyl meloxicam & & & 84.2 & $65.9 \pm 1.8$ & & \\
\hline metronidazole & $10 ; 11 \pm 1$ & 5.4 & 11.9 & & $0.00 \pm 0.01$ & \\
\hline nitrazepam & & 82.3 & 76.7 & n.d. ${ }^{c}$ & $0.05 \pm 0.03$ & $0.98 \pm 0.06$ \\
\hline oxazepam & 98.4 & 94.2 & $79.9,89.5$ & n.d. ${ }^{c}$ & $0.06 \pm 0.03$ & $0.27 \pm 0.03$ \\
\hline phenylbutazone & $97.8 ; 98-99$ & 98.4 & 99.9 & $96.3 \pm 0.5$ & $0.53 \pm 0.05$ & \\
\hline$C$-methyl phenylbutazone & & & 85.0 & $64.1 \pm 1.8$ & & \\
\hline O-methyl phenylbutazone & & & 92.9 & $92.9 \pm 1.9$ & & \\
\hline physostigmine & & & 20.0 & $9.7 \pm 6.6$ & $0.05 \pm 0.03$ & \\
\hline piroxicam & $99 ; 99$ & 96.8 & 100.0 & $93.3 \pm 0.3$ & $0.00 \pm 0.04$ & $0.55 \pm 0.09$ \\
\hline procaine & 6 & 36.0 & 21.0 & $6.4 \pm 0.4$ & $0.02 \pm 0.06$ & $0.00 \pm 0.06$ \\
\hline propranolol & $87 \pm 6 ; 87$ & 62.0 & 62.5 & & n.d. ${ }^{a}$ & \\
\hline sulindac & $94 ; 93.5$ & 92.0 & 98.2 & $64.9 \pm 6.9$ & $0.16 \pm 0.06$ & \\
\hline tenoxicam & & & 100.0 & $96.8 \pm 0.0$ & $0.13 \pm 0.11^{d}$ & $0.72 \pm 0.09$ \\
\hline trimethoprim & $37.5 ; 41.5$ & 37.6 & 37.3 & $3.1 \pm 4.6$ & $0.01 \pm 0.02$ & \\
\hline warfarin & $99 \pm 1 ; 99$ & 97.9 & $99.9,100.0$ & $91.5 \pm 0.7$ & $0.41 \pm 0.05$ & \\
\hline
\end{tabular}

${ }^{a}$ Experimental data has been measured using a racemic compound. ${ }^{b}$ HSA binding could not be determined due to chemical decomposition during incubation. ${ }^{c} \mathrm{HSA}$ suppressed the absorbance of the API, and $\mathrm{p} K_{\mathrm{a}, \mathrm{HSA}}$ could not be determined. ${ }^{d}$ High standard deviations originate from extrapolated $\mathrm{p} K_{\mathrm{a}}$ values, out of the measurement range of UV-pH titration.

where no interference with HSA absorption bands was observed and thus evaluation of data was possible.

Comparison of the Results with Reference Values. To compare our results with data from orthogonal methods, we also measured HSA binding of the APIs using chromatographic measurements on an immobilized HSA column using rapid equilibrium dialysis (RED) and carried out molecular docking of some APIs (Figure 3) into the crystal structure of HSA. We found that in the case of compounds with high HSA binding, significant shifts $\left(\Delta \mathrm{p} K_{\mathrm{a}}>0.1\right)$ could be observed for at least one $\mathrm{p} K_{\mathrm{a}}$ value, while no change of $\mathrm{p} K_{\mathrm{a}}$ values can be expected for APIs with lower HSA binding (HSA\% less than 40\%). However, in some cases (e.g., diazepam (DZP)), the results of UV-pH titration $\left(\Delta \mathrm{p} K_{\mathrm{a}}=0.09\right)$ contradicted the data from orthogonal methods (HSA binding, >90\%).

Among the studied drugs, $\mathrm{p} K_{\mathrm{a}}$ shifts (from free to HSAbound form) around or greater than 0.4 units were observed for chloroquine ( $\mathrm{CHQ} \Delta \mathrm{p} K_{\mathrm{a} 2}, 0.75$ ), diclofenac (DIC; $\Delta \mathrm{p} K_{\mathrm{a}}$, 0.47 ), diflunisal (DIF; $\Delta \mathrm{p} K_{\mathrm{a} 2}, 0.38$ ), meloxicam (MEL; $\Delta \mathrm{p} K_{\mathrm{a} 2}$, 0.55 ), nitrazepam (NZP; $\Delta \mathrm{p} K_{\mathrm{a} 2}, 0.98$ ), phenylbutazone (PHB;
$\left.\Delta \mathrm{p} K_{\mathrm{a}}, 0.53\right)$, piroxicam (PIR; $\left.\Delta \mathrm{p} K_{\mathrm{a} 2}, 0.55\right)$, and tenoxicam (TEN; $\Delta \mathrm{p} K_{\mathrm{a} 2}, 0.72$ ). In each case, the $\mathrm{p} K_{\mathrm{a}}$ shifted toward a more acidic value, favoring the deprotonated form of the APIs when bound to HSA. To understand the structural basis of these changes, the available X-ray structures of human serum albumin (HSA) were scrutinized. From the mentioned APIs, co-crystallized structures with HSA exist for DIC (PDB: $4 Z 69^{50}$ ), DIF (PDB: $2 \mathrm{BXE}^{51}$ ), and PHB (PDB: $2 \mathrm{BXC}^{51}$ ). Notably, DIC and PHB bind to drug site I ("warfarin site"), while DIF binds to drug site II (indole-benzodiazepine site). Although the exact hydrogen positions are not available at the resolution of these structures, the immediate vicinity of the ligand protonatable groups to positively charged amino acids (such as the K195-K199-R218-R222 cluster in drug site I or R410-K414 in drug site II) strongly implies the preference toward the deprotonated forms of the APIs. The experimental binding modes were evaluated with the extra precision (XP) mode of Glide for both the protonated and deprotonated forms (refinement only): per-residue Coulomb interaction 
<smiles>CCN(CC)CCCC(C)Nc1ccnc2cc(Cl)ccc12</smiles>

CHQ<smiles>[R]OC(=O)Cc1ccccc1Nc1c(Cl)cccc1Cl</smiles>

DIC $(\mathrm{R}=\mathrm{H})$ DIC ethyl ester $(R=E t)$<smiles>[R7]OC(=O)c1cc(-c2ccc(F)cc2F)ccc1O</smiles>

DIF ethyl ester $(R=E t)$<smiles>CN1C(=O)CN=C(c2ccccc2)c2cc(Cl)ccc21</smiles>

DZP<smiles>[R7]C1=C(C(=O)Nc2ncc(C)s2)N(C)S(=O)(=O)c2ccccc21</smiles>

MEL $(R=H)$

O-Methyl MEL $(R=M e)$

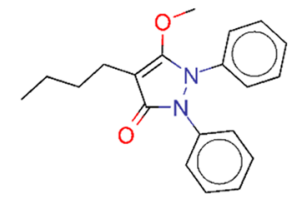

O-Methyl PHB<smiles>O=C1CN=C(c2ccccc2)c2cc([N+](=O)[O-])ccc2N1</smiles>

NZP<smiles>[R]C1(CCCC)C(=O)N(c2ccccc2)N(c2ccccc2)C1=O</smiles>

PHB $(\mathrm{R}=\mathrm{H})$

C-Methyl PHB $(\mathrm{R}=\mathrm{Me})$<smiles>CN1C(C(=O)Nc2ccccn2)=C(O)c2ccccc2S1(=O)=O</smiles>

PIR<smiles>CN1C(C(=O)Nc2ccccn2)=C(O)c2sccc2S1(=O)=O</smiles>

0

Figure 3. Structure of APIs investigated by molecular modeling studies. CHQ chloroquine; DIC, diclofenac; DIF, diflunisal; DZP, diazepam; MEL, meloxicam; NZP, nitrazepam; PHB, phenylbutazone; PIR, piroxicam; and TEN, tenoxicam.

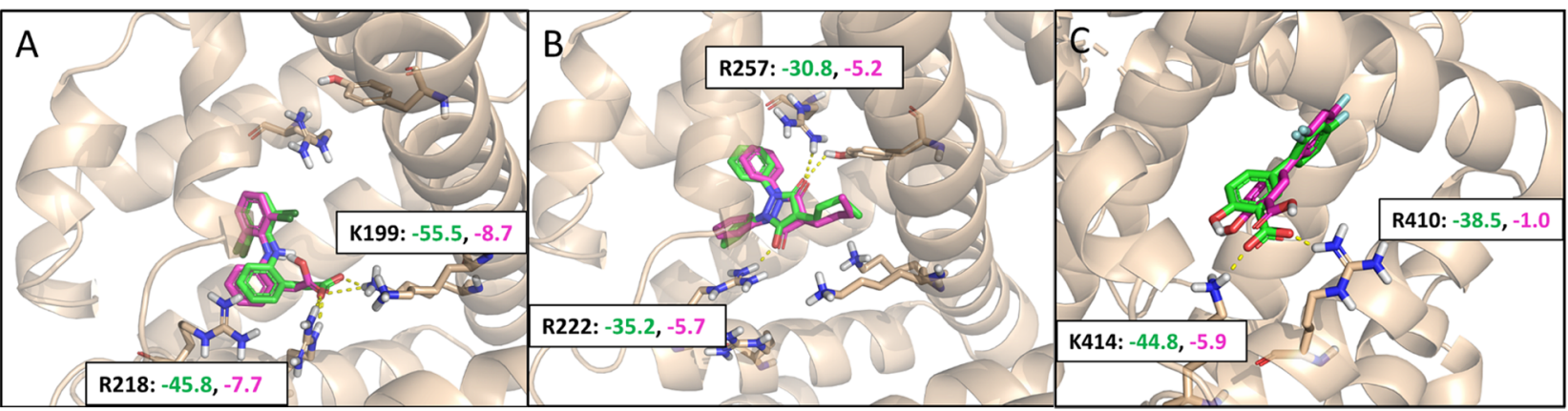

Figure 4. Refined experimental binding modes for the deprotonated (green) and protonated (magenta) forms of (A) diclofenac, (B) phenylbutazone, and (C) diflunisal (C). Coulomb interaction scores with the most important interacting residues are shown in matching colors, the smaller the better. (While in phenylbutazone, formally, the ring $\mathrm{CH}$ gets deprotonated, and practically, the negative charge is located on one of the oxo groups due to tautomerization).

scores between the ligands and the mentioned charged residues confirm this implication (Figure 4).

For the remaining five APIs, Glide XP was used to predict their binding modes in the two drug sites of HSA by docking to the X-ray structures $2 \mathrm{BXC}$ and $2 \mathrm{BXE}$. The poses were inspected with regard to the vicinity of the protonatable groups (specifically, the ones with the significant $\mathrm{p} K_{\mathrm{a}}$ shifts) to potential ionic interaction partners. For four APIs, such a binding pose was identified in drug site I (as the most favorable binding pose in each case), and the differences of the Coulomb interaction scores confirm the preference toward the deprotonated forms (Figure 5). For CHQ (the only API with a formal positive charge in its protonated form), no such binding mode was identified in either drug site. We propose that in the case of $\mathrm{CHQ}$ the deprotonated form is favored because ligand entry to both drug sites is hindered for the protonated form due to the repulsive interactions with the positively charged residue clusters at the entry points of the sites (K195-K199-R218-R222 in drug site I and R410-K414 in drug site II, see also Figure 4). ${ }^{51}$

Due to the contradictory UV-pH titration results of DZP, to find possible explanations, we compared X-Ray structures (where available) and predicted binding modes of DZP and its structural analogue NZP (Figure 6). In the X-ray structure 2BXD, DZP occupies drug site II (A), with its only protonatable nitrogen being too far from the $\mathrm{R} 485$ residue to make direct contact. Although its predicted binding mode in site I (B) would justify a $\mathrm{p} K_{\mathrm{a}}$ shift (the same nitrogen being only $3.0 \AA$ away from R257), binding to this site is not observed in the crystal structure, suggesting that site II is clearly preferred. Thus, the protonatable nitrogen will not be able to directly interact with HSA, which can explain the smaller than expected $\mathrm{p} K_{\mathrm{a}}$ shift. On the contrary, in the predicted binding mode of NZP to drug site II (C), the deprotonatable amide nitrogen is too far from R410 to make direct contact, but the predicted binding mode in drug site I (D) nicely supports the observed $\mathrm{p} K_{\mathrm{a}}$ shift of 0.56 units (by 


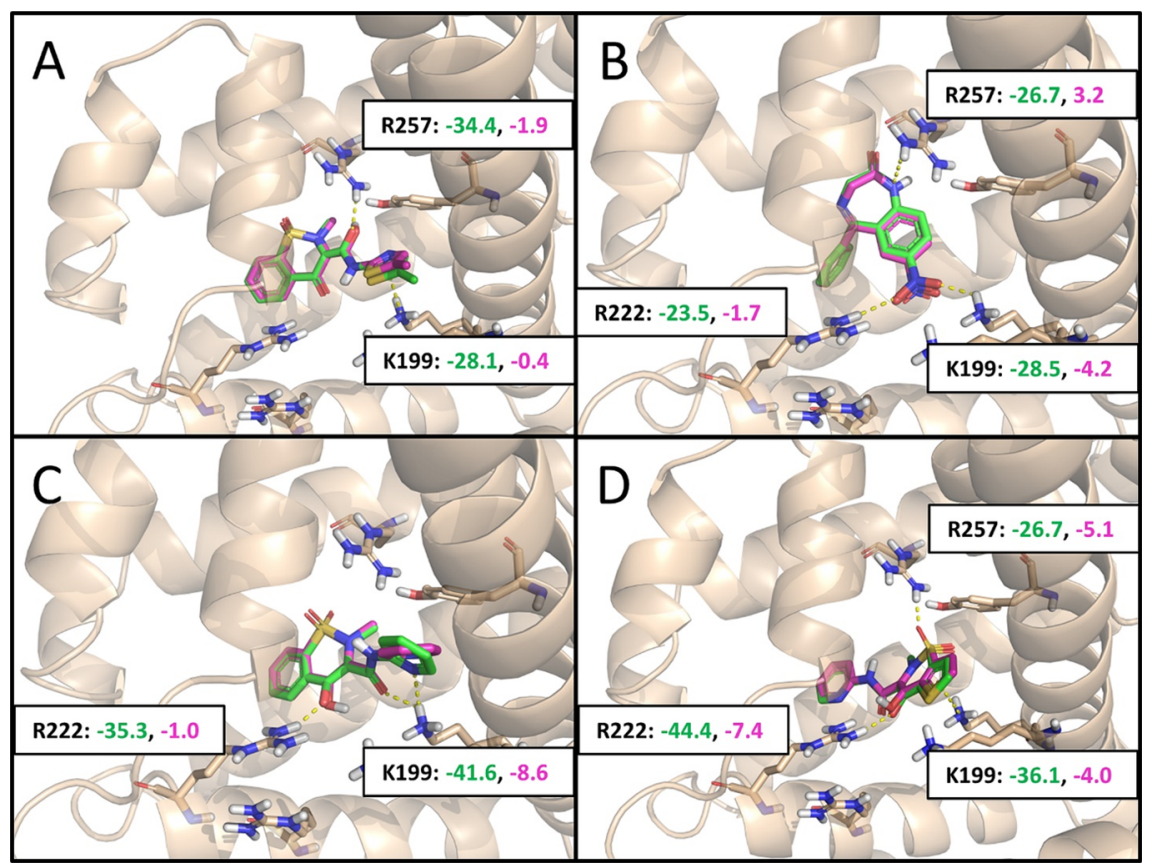

Figure 5. Refined predicted binding modes for the deprotonated (green) and protonated (magenta) forms of (A) meloxicam, (B) nitrazepam, (C) piroxicam, and (D) tenoxicam. Coulomb interaction scores with the most important interacting residues are shown in matching colors, the smaller the better.

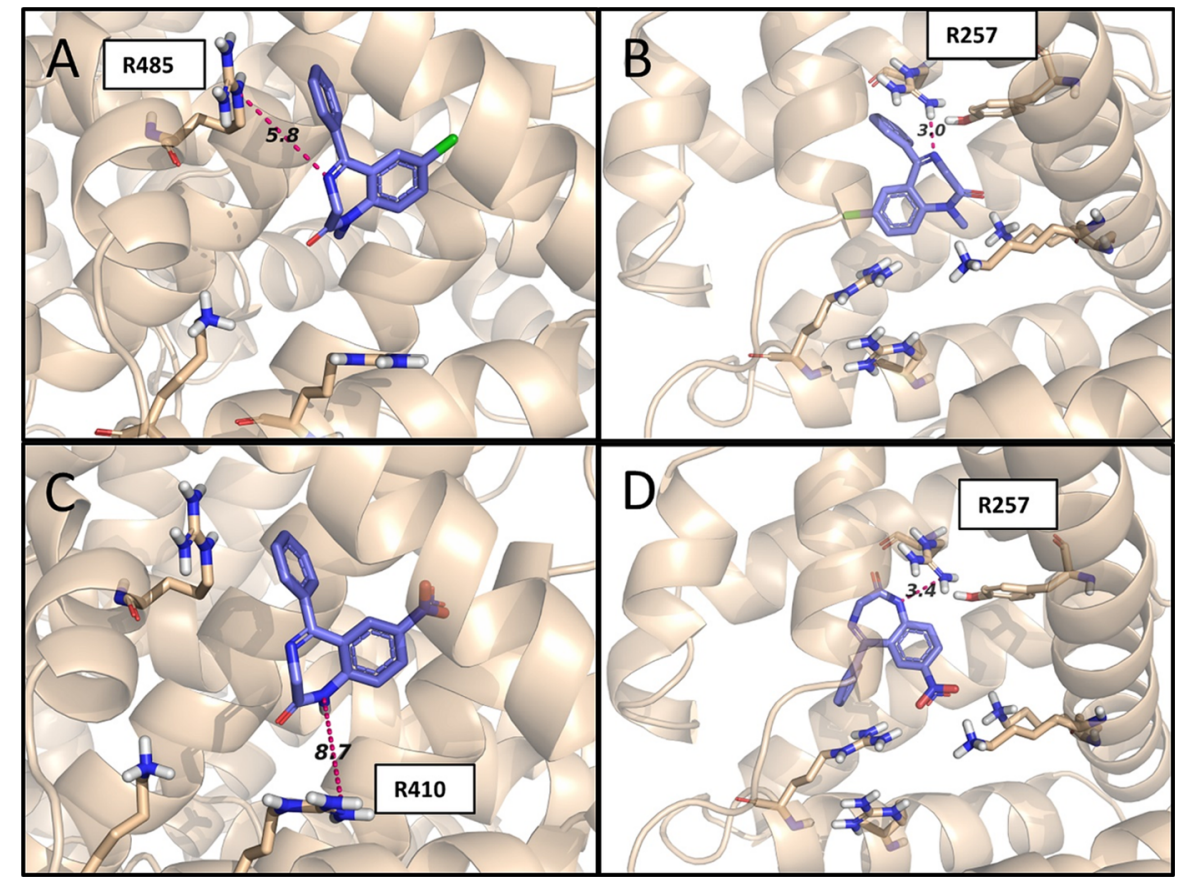

Figure 6. Comparison of crystallographic and predicted binding modes of (A, B) diazepam and (C, D) nitrazepam, with distances of the relevant protonatable groups to the closest charged residues.

placing the amide nitrogen $3.4 \AA$ away from R257), suggesting the preference of NZP toward drug site I.

Use of UV-pH Titration To Assist Medicinal Chemistry. As the previous examples show, UV-pH titration combined with molecular modeling can be used to identify the role of ionization centers in the formation of strong APIHSA interactions. The information gathered this way might be used to help chemists to design molecules with decreased HSA binding, which might improve the API pharmacokinetics and increase their bioavailability. For validation purposes, some of the APIs with considerable $\mathrm{p} K_{\mathrm{a}}$ shifts (DIC, DIF, MEL, and $\mathrm{PHB}$ ) were modified by ester formation or alkylation to neutralize their protonatable groups; these analogues were evaluated with the same protocols as described above.

The chromatographic measurements showed a significant decrease in retention time for each modified API, indicating a lower HSA binding affinity (Table 2 and Figure 7). We observed moderate decreases in binding for DIC ethyl ester 
DIC

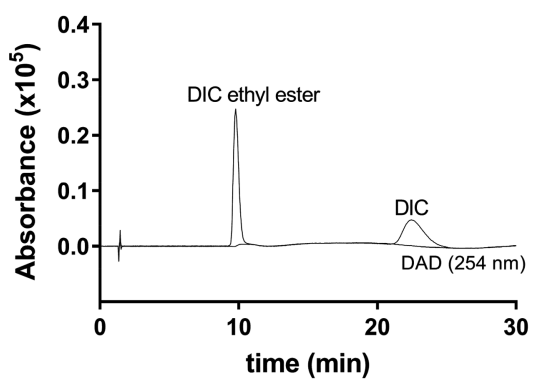

MEL

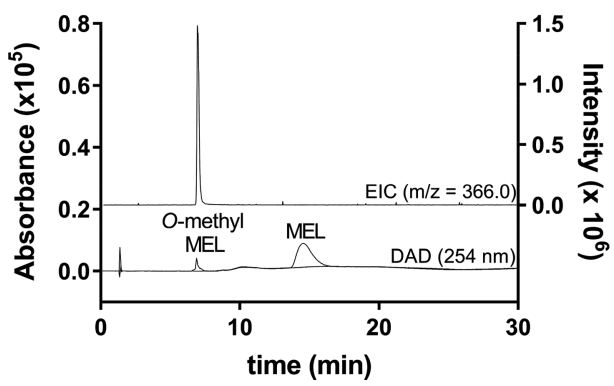

DIF

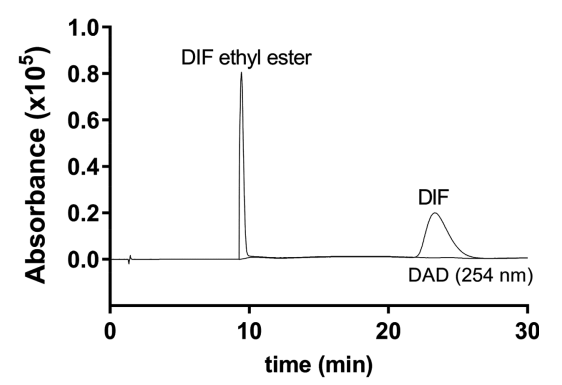

PHB

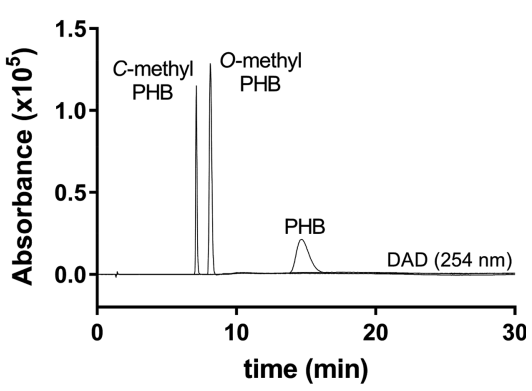

Figure 7. Chromatograms of diclofenac (DIC), diflunisal (DIF), meloxicam (MEL), phenylbutazone (PHB), and their modified forms with neutralized ionization centers. (Due to low absorbance of $O$-methyl MEL, its extracted ion chromatogram (EIC) $(\mathrm{m} / z=366.0)$ was also used for peak identification).

$(100 \% \rightarrow 98.1 \%)$ and DIF ethyl ester $(100 \% \rightarrow 97.5 \%)$ and extensive decreases in the case of O-methyl MEL $(99.9 \% \rightarrow$ 84.2\%), O-methyl PHB (99.9\% $\rightarrow$ 92.9\%), and C-methyl PHB $(99.9 \% \rightarrow 85.0 \%)$. RED measurements also showed significant decreases in the binding of modified MEL (99.9\% $\rightarrow 65.9 \%)$ and $\mathrm{PHB}(99.9 \% \rightarrow$ 92.9\% (O-methyl $\mathrm{PHB})$ and $99.9 \% \rightarrow$ 85.0\% (C-methyl PHB)), while HSA binding could not be determined this way for the esters of DIC and DIF due to their instability under the measurement conditions of RED (Table 2).

To further support the experimental results, molecular docking studies have also been carried out to compare binding modes of the analogues. For the ethyl ester of DIF, the $O$ - and $C$-methylated PHB, and the ethyl ester of DIC, the top binding modes predicted by Glide XP docking were closely similar to their respective unmodified counterparts. Nonetheless, the Coulomb interaction scores against the charged residues were small, as expected (Figure 8). For O-methyl MEL, unrestrained Glide XP docking could not identify a binding mode similar to that of the unmodified API. When restricted to the reference binding mode of meloxicam, the modified analogue exhibits repulsive Coulomb interaction scores, while in its unrestricted binding mode, the interaction scores confer slightly and in one case (K199), moderately attractive contributions, similar to the other analogues.

As the results of experimental measurements and molecular modeling show, we succeeded in using UV-pH titration as a screening tool for identifying structural moieties that make major contribution in formation of complexes with strong binding. By the modification of the APIs, the ionization centers responsible for strong interactions with HSA could be neutralized, resulting in a lower HSA binding. Since even a few percent decreases have a considerable effect on the distribution of APIs, ${ }^{5}$ the observed decreases in HSA binding (from $2-3$ to $10-35 \%$ ) support the technique's applicability to help the design of novel molecules with favorable pharmacokinetic behavior.

\section{CONCLUSIONS}

In this study, we demonstrated the applicability of UV-pH titration as an orthogonal method for the identification of APIs with high-affinity binding. This fast and cost-effective method can be used as a screening assay in the case of molecules containing ionization centers, providing binding data faster than conventional methods. We showed that the observed $\mathrm{p} K_{\mathrm{a}}$ shifts $\left(\Delta \mathrm{p} K_{\mathrm{a}}\right)$ are proportional to HSA binding of APIs. In the case of multiprotic molecules, by means of molecular docking, we demonstrated that the $\mathrm{p} K_{\mathrm{a}}$ shifts of different sizes provide structural information on the binding mode of the API. To elucidate the significance of ionization centers of molecules, we also investigated modified analogues with neutralized protonation centers. The results clearly showed that decreased protein binding can be achieved by this approach, resulting in molecules with improved pharmacokinetics. Therefore, the UV-pH titration method combined with an in silico support might be used as a novel medicinal chemistry tool to assist researchers in the rational drug design to decrease the high attrition rate in later stages of drug discovery. In the future, besides screening for APIs with high-affinity binding, this method might also be used for comparison of binding of a specific API with different kinds of modified HSA derivatives or in the case of different formulations of HSA.

\section{EXPERIMENTAL SECTION}

Materials. Analytical grade solvents such as acetonitrile $(\mathrm{MeCN})$, dimethyl sulfoxide (DMSO), ethanol (absolute), formic acid, trifluoroacetic acid (TFA), and potassium hydroxide $(\mathrm{KOH})$ were purchased from Merck KGaA (Darmstadt, Germany). Analytical grade 2-propanol (IPA), $0.5 \mathrm{M}$ hydrochloric acid, and $0.5 \mathrm{M}$ potassium hydroxide were purchased from Honeywell International 


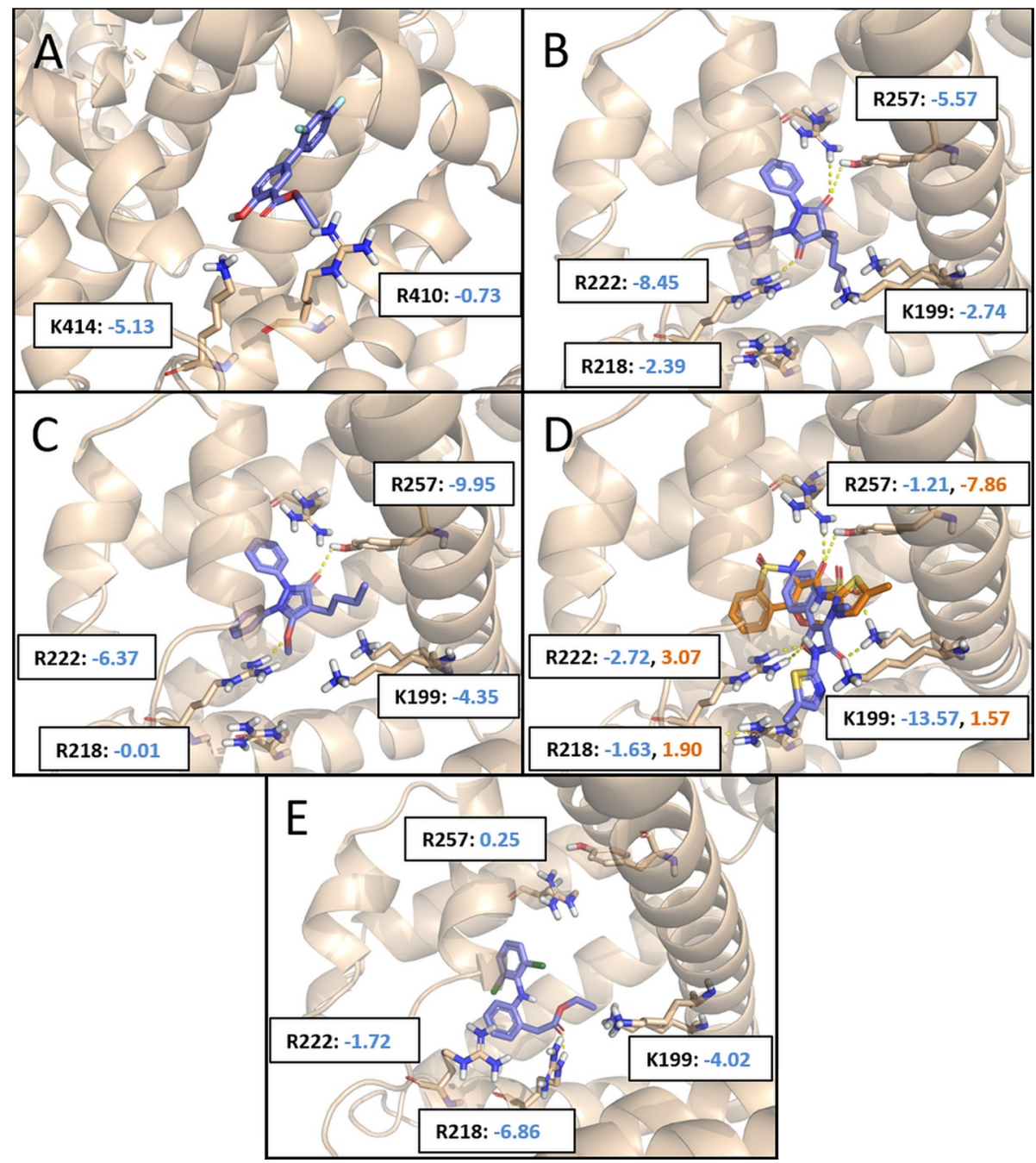

Figure 8. Predicted binding modes for (A) diflunisal ethyl ester, (B) C-methyl phenylbutazone, (C) O-methyl phenylbutazone, (D) $O$-methyl meloxicam, and (E) diclofenac ethyl ester. For methoxy-meloxicam, the binding mode with the core position restricted to the binding mode of meloxicam is shown in orange. Coulomb interaction scores with the most important charged residues are shown in matching colors (the smaller the better): these are mostly slightly attractive (and in some cases, slightly repulsive), similar to the protonated forms of the original APIs. By comparison, the deprotonated forms of the APIs exhibit large negative (strongly attractive) Coulomb contributions (see Figures 4 and 5).

Inc. (New Jersey, USA). Albumin from human serum (lyophilized powder, $\geq 97 \%$ (agarose gel electrophoresis) cat. no.: A9511), ammonium acetate $\left(\mathrm{NH}_{4} \mathrm{OAc}\right)$, dichloromethane (DCM), ethyl acetate (EtOAc), methyl iodide (MeI), phosphate-buffered saline (PBS) powder, potassium chloride, and the reference materials (acetaminophen, amodiaquine dihydrochloride dihydrate, amoxicillin, ampicillin, antipyrine, aspirin, atenolol, captopril, carbamazepine, cefotaxime sodium, cefuroxime sodium, cephalexin, chloroquine diphosphate, chlorothiazide, chlorpromazine hydrochloride, cimetidine hydrochloride, clonidine hydrochloride, diazepam, diclofenac sodium, diflunisal, diltiazem hydrochloride, diphenhydramine hydrochloride, famotidine, furosemide, imipramine hydrochloride, indomethacin, isoniazid, isoxicam, ketoconazole, meloxicam, metronidazole, naproxen, nifedipine, nitrazepam, oxazepam, phenylbutazone, phenytoin, physostigmine, piroxicam, procaine hydrochloride, propranolol hydrochloride, ranitidine hydrochloride, rifampin, sulfamerazine, sulfamethoxazole, sulindac, terbutaline hemisulfate, trimethoprim, and warfarin) were purchased from Sigma-Aldrich Co., Ltd. (Budapest, Hungary). Diclofenac ethyl ester, ketorolac tromethamine, and $\mathrm{O}$-methyl meloxicam were purchased from Toronto Research Chemicals Inc. (North York, Toronto, Canada). Lornoxicam and tenoxicam were purchased from Carbosynth Ltd. (Compton, Berkshire, United Kingdom). O-methyl phenylbutazone was purchased from Ambinter c/o Greenpharma S.A.S. (Orléans, France).
Diflunisal ethyl ester and $C$-methyl phenylbutazone were synthesized at Gedeon Richter Plc. Compounds possessed a purity of $>95 \%$ by means of HPLC. (Diflunisal ethyl ester: SHIMADZU prominence modular HPLC system equipped with a photodiode array detector (PDA) and a mass spectrometer equipped with an electrospray ionization source (ESI); column: CORTECS C18+, $90 \AA$, $2.7 \mu \mathrm{m}$ $(3.0 \times 50 \mathrm{~mm})$; retention time $=3.89 \mathrm{~min}$; peak area, $98.76 \%$; eluent A, $0.1 \%(\mathrm{v} / \mathrm{v})$ formic acid in water; eluent $\mathrm{B}, \mathrm{MeCN} /$ water 95:5 (v/v) with $0.1 \%(\mathrm{v} / \mathrm{v})$ formic acid; gradient: $0-4.5 \mathrm{~min} / 2-100 \% \mathrm{~B}$ and $4.5-5.6 \mathrm{~min} / 100 \% \mathrm{~B}$; flow rate of $1.25 \mathrm{~mL} / \mathrm{min}$; detection at $220 \pm 4$ $\mathrm{nm}$; column temperature: $40{ }^{\circ} \mathrm{C}$. $C$-methyl phenylbutazone: Agilent 1200 liquid chromatography system equipped with a diode array detector and coupled with an Agilent 6410 triple quadrupole mass spectrometer (QQQ-MS) equipped with an ESI source; column: Kinetex EVO C18, $100 \AA$, $2.6 \mu \mathrm{m}(3.0 \times 100 \mathrm{~mm})$; retention time $=$ $8.60 \mathrm{~min}$; peak area, $99.77 \%$; eluent A, $0.1 \%(\mathrm{v} / \mathrm{v})$ TFA in water; eluent $\mathrm{B}, \mathrm{MeCN} /$ water 95:5 (v/v) with $0.1 \%(\mathrm{v} / \mathrm{v})$ TFA; gradient: 0-15 $\mathrm{min} / 0-100 \% \mathrm{~B}$ and $15-18 \mathrm{~min} / 100 \% \mathrm{~B}$; flow rate of $1 \mathrm{~mL} /$ min; detection at $220 \pm 4 \mathrm{~nm}$; column temperature: $45{ }^{\circ} \mathrm{C}$.) For detailed information on their syntheses and confirmation of structures (NMR and HRMS), see the Supporting Information (Sections 4-6). Neutral linear buffer (NLB) was purchased from Pion Inc. (U.K.) Ltd. (Forrest Row, United Kingdom). In all experiments, distilled water 
was purified by the Millipore Milli-Q 140 gradient water purification system.

UV-pH Titration. The UV-pH titrations were performed using a fully automated SiriusT3 instrument (Pion Inc., Forest Row, U.K.). Spectrophotometric determination of $\mathrm{p} K_{\mathrm{a}}$ values was performed using the built-in fast $\mathrm{UV} \mathrm{p} K_{\mathrm{a}}$ method, the absorbance changes during the titrations were monitored by the dip-probe absorption spectroscopy (D-PAS) method, ${ }^{52,53}$ and evaluation and calculation of $\mathrm{p} K_{\mathrm{a}}$ values were performed by the SiriusT3Refine software (version 1.1.3.0., Pion Inc., Forest Row, U.K.). For the determination of $\mathrm{p} K_{\mathrm{a}}$ values in aqueous media, $5 \mu \mathrm{L}$ of $10 \mathrm{mM}$ DMSO solution of the samples was titrated from $\mathrm{pH} 2.0$ to $\mathrm{pH} 12.0$ in $1.5 \mathrm{~mL}$ ionic strength adjusted water (ISA-water: $0.15 \mathrm{M} \mathrm{KCl}$; the initial sample concentration is approximately $33.3 \mu \mathrm{M})$. In the case of determination of $\mathrm{p} K_{\mathrm{a}}$ values in the presence of HSA $\left(\mathrm{pK}_{\mathrm{a}, \mathrm{HSA}}\right)$, a modified fast UV assay was used: ISA-water solutions containing HSA $(33.3 \mu \mathrm{M}$, with a $1: 1$ nominal molar ratio of HSA and APIs) were added manually in advance to the titration vials. All measurements were performed under a nitrogen atmosphere at $T=25.0 \pm 0.1{ }^{\circ} \mathrm{C}$. The $\mathrm{pH}$ region $2.0-10.0$ and the spectral region of $250-450 \mathrm{~nm}$ were used in the analysis, and the results were calculated from a minimum of three replicates in each case.

Molecular Docking. Ligand and protein structures were prepared with the standard tools of the Schrödinger software package, ${ }^{54-56}$ based on the OPLS3 force field. ${ }^{57}$ For ligand docking and the generation of per-residue interaction scores, the extra precision mode (XP) of Glide was used. ${ }^{58,59}$ The publicly available PDB structures 2BXC, $2 \mathrm{BXE},{ }^{51}$ and $4 \mathrm{Z} 69^{50}$ were used for evaluating the experimental binding modes of PHB, DIF, and DIC, respectively. For the additional five APIs, the structures $2 \mathrm{BXC}$ and $2 \mathrm{BXE}$ were used to generate predicted binding modes with Glide XP, after validating them by redocking their cognate ligands into the respective binding pockets. (RMSD values between experimental and predicted poses were 1.40 and $1.01 \AA$ for $2 \mathrm{BXC}$ and 2BXE, respectively, and $5.60 \AA$ for $4 \mathrm{Z} 69$; therefore, this structure was omitted from further use.) The best identified binding pose was refined for both the protonated and deprotonated forms of the APIs.

For detailed description of HSA-binding measurement by RED and biomimetic chromatography, see the Supporting Information.

\section{ASSOCIATED CONTENT}

\section{(s) Supporting Information}

The Supporting Information is available free of charge at https://pubs.acs.org/doi/10.1021/acs.jmedchem.0c00046.

Results of UV-pH titrations in the presence and absence of HSA, results of HSA-binding measurements by RED and biomimetic chromatography (CHIRALPAK HSA column), comparison of the HPLC systems used for HPLC-HSA measurements, and synthesis and structural confirmation (NMR and HRMS) of diflunisal ethyl ester and $C$-methyl phenylbutazone (PDF)

Molecular formula strings of different APIs (CSV)

\section{AUTHOR INFORMATION}

\section{Corresponding Author}

György T. Balogh - Department of Chemical and Environmental Process Engineering, Budapest University of Technology and Economics, 1111 Budapest, Hungary; Chemistry Department, Gedeon Richter Plc., 1107 Budapest, Hungary; Department of Pharmacodynamics and Biopharmacy, University of Szeged, 6720 Szeged, Hungary; (ㄱ) orcid.org/ 0000-0001-8273-1760; Phone: +36 1463 2174; Email: gytbalogh@mail.bme.hu
Authors

Gergó Dargó - Department of Chemical and Environmental Process Engineering, Budapest University of Technology and Economics, 1111 Budapest, Hungary; Chemistry Department, Gedeon Richter Plc., 1107 Budapest, Hungary

Dávid Bajusz - Medicinal Chemistry Research Group, Research Centre for Natural Sciences, 1117 Budapest, Hungary; (1) orcid.org/0000-0003-4277-9481

Kristóf Simon - Department of Organic Chemistry and Technology, Budapest University of Technology and Economics, 1111 Budapest, Hungary

Judit Müller - Medicinal Chemistry Laboratory II, Gedeon

Richter Plc., 1107 Budapest, Hungary

Complete contact information is available at:

https://pubs.acs.org/10.1021/acs.jmedchem.0c00046

\section{Author Contributions}

The manuscript was written through contributions of all authors. All authors have given approval to the final version of the manuscript.

Notes

The authors declare no competing financial interest.

\section{ACKNOWLEDGMENTS}

G.D. thanks the Gedeon Richter Talentum Foundation for the financial support. We are grateful to Gyula Beke for his assistance in synthetizing modified APIs, to Áron Szigetvári and Prof. Csaba Szántay Jr. for NMR measurements, and to János Kóti for HRMS measurements.

\section{ABBREVIATIONS}

CE, capillary electrophoresis; CHQ chloroquine; DIC, diclofenac; DIF, diflunisal; DZP, diazepam; DAD, diode array detector; ED, equilibrium dialysis; EIC, extract ion chromatogram; EtOAc, ethyl acetate; HT, high throughput; IPA, 2-propanol; ISA, ionic strength adjusted; $\mathrm{KOH}$, potassium hydroxide; LT, low throughput; $\mathrm{MeCN}$, acetonitrile; MeI, methyl iodide; MEL, meloxicam; MT, medium throughput; NLB, neutral linear buffer; NSB, nonspecific binding; NZP, nitrazepam; PDA, photodiode array (detector); PHB, phenylbutazone; PIR, piroxicam; RED, rapid equilibrium dialysis; SPME, solid-phase microextraction; TEN, tenoxicam; TFA, trifluoroacetic acid; UF, ultrafiltration

\section{REFERENCES}

(1) Di, L.; Kerns, E. H. Drug-Like Properties: Concepts, Structure Design and Methods from ADME to Toxicity Optimization; Elsevier Inc., 2016.

(2) Fessey, R. E.; Austin, R. P.; Barton, P.; Davis, A. M.; Wenlock, M. C. The Role of Plasma Protein Binding in Drug Discovery. In Pharmacokinetic Profiling in Drug Research; Wiley-VCH Verlag GmbH \& Co. KGaA: Weinheim, Germany, 2007; pp 119-141.

(3) Trainor, G. L. The Importance of Plasma Protein Binding in Drug Discovery. Expert Opin. Drug Discov. 2007, 2, 51-64.

(4) Goodman \& Gilman's The Pharmacological Basis of Therapeutics, 13th ed.; Brunton, L. L., Hilal-Dandan, R., Knollmann, B. C., Eds.; McGraw-Hill Education, 2018.

(5) Sun, H.; Zhao, H. Physiologic Drug Distribution and Protein Binding. In Applied Biopharmaceutics \& Pharmacokinetics; Shargel, L., Yu, A. B. C., Eds.; McGraw-Hill Education, 2016.

(6) Fox, S., Blood, I. Heart, and Circulation. In Human Physiology; McGraw-Hill Education, 2016.

(7) Betts, J. G.; Desaix, P.; Johnson, E. W.; Johnson, J. E.; Korol, O.; Kruse, D.; Poe, B.; Wise, J.; Womble, M. D.; Young, K. A. The 
Cardiovascular System: Blood. In Anatomy \& Physiology; OpenStax, 2013.

(8) Fanali, G.; di Masi, A.; Trezza, V.; Marino, M.; Fasano, M.; Ascenzi, P. Human Serum Albumin: From Bench to Bedside. Mol. Aspects Med. 2012, 33, 209-290.

(9) Di, L.; Kerns, E. H.; Di, L.; Kerns, E. H. Chapter 14 - Plasma and Tissue Binding. In Drug-Like Properties; Academic Press, 2016; pp 219-228.

(10) Quinlan, G. J.; Martin, G. S.; Evans, T. W. Albumin: Biochemical Properties and Therapeutic Potential. Hepatology 2005, 41, 1211-1219.

(11) Kragh-Hansen, U.; Chuang, V. T. G.; Otagiri, M. Practical Aspects of the Ligand-Binding and Enzymatic Properties of Human Serum Albumin. Biol. Pharm. Bull. 2002, 25, 695-704.

(12) Jahanban-Esfahlan, A.; Davaran, S.; Moosavi-Movahedi, A. A.; Dastmalchi, S. Investigating the Interaction of Juglone (5-Hydroxy-1, 4-Naphthoquinone) with Serum Albumins Using Spectroscopic and in Silico Methods. J. Iran. Chem. Soc. 2017, 14, 1527-1540.

(13) Roufegarinejad, L.; Amarowicz, R.; Jahanban-Esfahlan, A. Characterizing the Interaction between Pyrogallol and Human Serum Albumin by Spectroscopic and Molecular Docking Methods. J. Biomol. Struct. Dyn. 2018, 37, 2766-2775.

(14) Christensen, H.; Baker, M.; Tucker, G. T.; Rostami-Hodjegan, A. Prediction of Plasma Protein Binding Displacement and Its Implications for Quantitative Assessment of Metabolic Drug-Drug Interactions from in Vitro Data. J. Pharm. Sci. 2006, 95, 2778-2787.

(15) Birkett, D. J.; Myers, S. P.; Sudlow, G. Effects of Fatty Acids on Two Specific Drug Binding Sites on Human Serum Albumin. Mol. Pharmacol. 1977, 13, 987-992.

(16) Sudlow, G.; Birkett, D. J.; Wade, D. N. Further Characterization of Specific Drug Binding Sites on Human Serum Albumin. Mol. Pharmacol. 1976, 12, 1052-1061.

(17) Yamasaki, K.; Maruyama, T.; Kragh-Hansen, U.; Otagiri, M. Characterization of Site I on Human Serum Albumin: Concept about the Structure of a Drug Binding Site. Biochim. Biophys. Acta - Protein Struct. Mol. Enzymol. 1996, 1295, 147-157.

(18) Zhivkova, Z. Studies on Drug - Human Serum Albumin Binding: The Current State of the Matter. Curr. Pharm. Des. 2015, 21, $1817-1830$.

(19) Bohnert, T.; Gan, L.-S. Plasma Protein Binding: From Discovery to Development. J. Pharm. Sci. 2013, 102, 2953-2994.

(20) Rolan, P. Plasma Protein Binding Displacement InteractionsWhy Are They Still Regarded as Clinically Important? Br. J. Clin. Pharmacol. 1994, 37, 125-128.

(21) Bowman, C. M.; Benet, L. Z. An Examination of Protein Binding and Protein-Facilitated Uptake Relating to in Vitro-in Vivo Extrapolation. Eur. J. Pharm. Sci. 2018, 123, 502-514.

(22) Baker, M.; Parton, T. Kinetic Determinants of Hepatic Clearance: Plasma Protein Binding and Hepatic Uptake. Xenobiotica 2007, 37, 1110-1134.

(23) Talbert, A. M.; Tranter, G. E.; Holmes, E.; Francis, P. L. Determination of Drug-Plasma Protein Binding Kinetics and Equilibria by Chromatographic Profiling: Exemplification of the Method Using 1-Tryptophan and Albumin. Anal. Chem. 2002, 74, 446-452.

(24) Svennebring, A. The Connection Between Plasma Protein Binding and Acute Toxicity as Determined by the LD 50 Value. Drug Dev. Res. 2016, 77, 3-11.

(25) Ramanathan, V.; Vachharajani, N. Protein Binding in Drug Discovery and Development. In Evaluation of Drug Candidates for Preclinical Development; John Wiley \& Sons, Inc.: Hoboken, NJ, USA, 2010; Vol. 13, pp 135-167.

(26) Buscher, B.; Laakso, S.; Mascher, H.; Pusecker, K.; Doig, M.; Dillen, L.; Wagner-Redeker, W.; Pfeifer, T.; Delrat, P.; Timmerman, P. Bioanalysis for Plasma Protein Binding Studies in Drug Discovery and Drug Development: Views and Recommendations of the European Bioanalysis Forum. Bioanalysis 2014, 6, 673-682.
(27) Ronzetti, M.; Baljinnyam, B.; Yasgar, A.; Simeonov, A. Testing for Drug-Human Serum Albumin Binding Using Fluorescent Probes and Other Methods. Expert Opin. Drug Discov. 2018, 13, 1005-1014. (28) Sebille, B. Methods of Drug Protein Binding Determinations. Fundam. Clin. Pharmacol. 1990, 4, 151s-161s.

(29) Wan, H.; Rehngren, M. High-Throughput Screening of Protein Binding by Equilibrium Dialysis Combined with Liquid Chromatography and Mass Spectrometry. J. Chromatogr. A 2006, 1102, 125134.

(30) Blanchard, J.; Harvey, S. Comparison of Ultrafiltration Devices for Assessing Theophylline Protein Binding. Ther. Drug Monit. 1990, 12, 398-403.

(31) Cole, J. L.; Lary, J. W.; Moody, T. P.; Laue, T. M. Analytical Ultracentrifugation: Sedimentation Velocity and Sedimentation Equilibrium. In Methods in Cell Biology; Elsevier, 2008; Vol. 84, pp 143-179.

(32) Wan, H.; Bergström, F. High Throughput Screening of DrugProtein Binding in Drug Discovery. J. Liq. Chromatogr. Relat. Technol. 2007, 30, 681-700.

(33) Li, Y.-F.; Zhang, X.-Q.; Hu, W.-Y.; Li, Z.; Liu, P.-X.; Zhang, Z.Q. Rapid Screening of Drug-Protein Binding Using High-Performance Affinity Chromatography with Columns Containing Immobilized Human Serum Albumin. J. Anal. Methods Chem. 2013, 2013, 1-7.

(34) Noctor, T. A. G.; Diaz-Perez, M. J.; Wainer, I. W. Use of a Human Serum Albumin-Based Stationary Phase for High-Performance Liquid Chromatography as a Tool for the Rapid Determination of Drug-Plasma Protein Binding. J. Pharm. Sci. 1993, 82, 675-676.

(35) Danon, A.; Chen, Z. Binding of Imipramine to Plasma Proteins: Effect of Hyperlipoproteinemia. Clin. Pharmacol. Ther. 1979, 25, 316-321.

(36) Lucas, L. H.; Larive, C. K. Measuring Ligand-Protein Binding Using NMR Diffusion Experiments. Concepts Magn. Reson. Part A. 2004, 20A, 24-41.

(37) Gallo, M.; Matteucci, S.; Alaimo, N.; Pitti, E.; Orsale, M. V.; Summa, V.; Cicero, D. O.; Monteagudo, E. A Novel Method Using Nuclear Magnetic Resonance for Plasma Protein Binding Assessment in Drug Discovery Programs. J. Pharm. Biomed. Anal. 2019, 167, 2129.

(38) Zhu, L.; Yang, F.; Chen, L.; Meehan, E. J.; Huang, M. A New Drug Binding Subsite on Human Serum Albumin and Drug-Drug Interaction Studied by X-Ray Crystallography. J. Struct. Biol. 2008, 162, 40-49.

(39) Wan, H.; Thompson, R. A. Capillary Electrophoresis Technologies for Screening in Drug Discovery. Drug Discov. Today Technol. 2005, 2, 171-178.

(40) Lambrinidis, G.; Vallianatou, T.; Tsantili-Kakoulidou, A. In Vitro, in Silico and Integrated Strategies for the Estimation of Plasma Protein Binding. A Review. Adv. Drug Delivery Rev 2015, 86, 27-45.

(41) Herbst, Z. M.; Shibata, S.; Fan, E.; Gelb, M. H. An Inexpensive, In-House-Made, Microdialysis Device for Measuring Drug-Protein Binding. ACS Med. Chem. Lett. 2018, 9, 279-282.

(42) Kieltyka, K.; McAuliffe, B.; Cianci, C.; Drexler, D. M.; Shou, W.; Zhang, J. Application of Cassette Ultracentrifugation Using NonLabeled Compounds and Liquid Chromatography-Tandem Mass Spectrometry Analysis for High-Throughput Protein Binding Determination. J. Pharm. Sci. 2016, 1036.

(43) Salgado, L. E. V.; Vargas-Hernández, C. Spectrophotometric Determination of the $\mathrm{PKa}$, Isosbestic Point and Equation of Absorbance vs. $\mathrm{PH}$ for a Universal $\mathrm{PH}$ Indicator. Am. J. Anal. Chem. 2014, 05, 1290-1301.

(44) Connors, K. A. Optical Absorption Spectroscopy. In Binding Constants: The Measurement of Molecular Complex Stability; WileyInterscience, 1987; pp 141-187.

(45) Goodman and Gilman's The Pharmacological Basis of Therapeutics, 10th ed.; Hardman, J. G., Limbird, L. E., Gilman, A. G., Eds.; McGraw-Hill, 2001.

(46) Zhang, F.; Xue, J.; Shao, J.; Jia, L. Compilation of 222 Drugs' Plasma Protein Binding Data and Guidance for Study Designs. Drug Discovery Today 2012, 475-485. 
(47) Singh, S. S.; Mehta, J. Measurement of Drug-Protein Binding by Immobilized Human Serum Albumin-HPLC and Comparison with Ultrafiltration. J. Chromatogr., B 2006, 834, 108-116.

(48) Valko, K.; Nunhuck, S.; Bevan, C.; Abraham, M. H.; Reynolds, D. P. Fast Gradient HPLC Method to Determine Compounds Binding to Human Serum Albumin. Relationships with Octanol/ Water and Immobilized Artificial Membrane Lipophilicity. J. Pharm. Sci. 2003, 92, 2236-2248.

(49) Hollósy, F.; Valkó, K.; Hersey, A.; Nunhuck, S.; Kéri, G.; Bevan, C. Estimation of Volume of Distribution in Humans from High Throughput HPLC-Based Measurements of Human Serum Albumin Binding and Immobilized Artificial Membrane Partitioning. J. Med. Chem. 2006, 49, 6958-6971.

(50) Zhang, Y.; Lee, P.; Liang, S.; Zhou, Z.; Wu, X.; Yang, F.; Liang, H. Structural Basis of Non-Steroidal Anti-Inflammatory Drug Diclofenac Binding to Human Serum Albumin. Chem. Biol. Drug Des. 2015, 86, 1178-1184.

(51) Ghuman, J.; Zunszain, P. A.; Petitpas, I.; Bhattacharya, A. A.; Otagiri, M.; Curry, S. Structural Basis of the Drug-Binding Specificity of Human Serum Albumin. J. Mol. Biol. 2005, 353, 38-52.

(52) Allen, R. I.; Box, K. J.; Comer, J. E. A.; Peake, C.; Tam, K. Y. Multiwavelength Spectrophotometric Determination of Acid Dissociation Constants of Ionizable Drugs. J. Pharm. Biomed. Anal. 1998, 17, 699-712.

(53) Tam, K. Y.; Takács-Novák, K. Multi-Wavelength Spectrophotometric Determination of Acid Dissociation Constants: A Validation Study. Anal. Chim. Acta 2001, 434, 157-167.

(54) Madhavi Sastry, G.; Adzhigirey, M.; Day, T.; Annabhimoju, R.; Sherman, W. Protein and Ligand Preparation: Parameters, Protocols, and Influence on Virtual Screening Enrichments. J. Comput.-Aided Mol. Des. 2013, 27, 221-234.

(55) Schrödinger Release 2018-4: Protein Preparation Wizard; Schrödinger, LLC: New York, NY, 2018.

(56) Schrödinger Release 2018-4: LigPrep; Schrödinger, LLC: New York, NY, 2018.

(57) Harder, E.; Damm, W.; Maple, J.; Wu, C.; Reboul, M.; Xiang, J. Y.; Wang, L.; Lupyan, D.; Dahlgren, M. K.; Knight, J. L.; Kaus, J. W.; Cerutti, D. S.; Krilov, G.; Jorgensen, W. L.; Abel, R.; Friesner, R. A. OPLS3: A Force Field Providing Broad Coverage of Drug-like Small Molecules and Proteins. J. Chem. Theory Comput. 2016, 12, 281-296.

(58) Friesner, R. A.; Murphy, R. B.; Repasky, M. P.; Frye, L. L.; Greenwood, J. R.; Halgren, T. A.; Sanschagrin, P. C.; Mainz, D. T. Extra Precision Glide: Docking and Scoring Incorporating a Model of Hydrophobic Enclosure for Protein-Ligand Complexes. J. Med. Chem. 2006, 49, 6177-6196.

(59) Schrödinger Release 2018-4: Glide; Schrödinger, LLC: New York, NY, 2018. 